\title{
An Analysis on Influence of the Realty Rents Brought by Urban Railway System: A Case Study of Guangzhou MTR 2nd Line
}

\author{
Qingwen Deng \\ School of Public Administration and Emergency Management, Jinan University, Guangzhou, China \\ Email: Qingman7@163.com
}

How to cite this paper: Deng, Q. W. (2020). An Analysis on Influence of the Realty Rents Brought by Urban Railway System: A Case Study of Guangzhou MTR 2nd Line. Open Journal of Social Sciences, 8, 316-329.

https://doi.org/10.4236/jss.2020.83029

Received: February 13, 2020

Accepted: March 22, 2020

Published: March 25, 2020

Copyright $\odot 2020$ by author(s) and Scientific Research Publishing Inc. This work is licensed under the Creative Commons Attribution International License (CC BY 4.0).

http://creativecommons.org/licenses/by/4.0/

\begin{abstract}
This paper took 215 samples along the Guangzhou metro line 2 as an example to research the impact of urban rail system on realty rental prices. Method of hedonic price model was employed to calculate the range of subway influencing the surrounding reality rental. Three conclusions can be drawn up: 1) Metro has no influence on the samples of the central zone, while it contributes to surrounding realty rental prices increment of the peripheral area; 2) For the peripheral area, rental houses are influenced within $1.5 \mathrm{~km}$. Realty rental prices have a significantly positive correlation with the distance of rental house away from the nearest subway station; 3) Average appreciation rate of monthly rents in the impact range reaches to $52.37 \%$. Furthermore, residential monthly rents of house within $0.5 \mathrm{~km}, 0.5-1 \mathrm{~km}$, and $1-1.5 \mathrm{~km}$ of subway stations are separately $56.9 \%, 49.2 \%$, and $51 \%$ higher than monthly rents of houses located outside the affected area. Based on the result above, several points of tactic advice to generate higher return in rentals for investors and to rent a proper house for tenants have been put forward.
\end{abstract}

\section{Keywords}

Realty Rents, Urban Railway System, Hedonic Price Model, Impact Range, Guangzhou Metro Line 2

\section{Introduction}

In 2015, the Ministry of Housing and Urban-Rural Development of China released a guideline to encourage and develop the residential leasing market. Local governments have introduced relevant policies in order to speed up development of the market for the home rental market, such as withdrawing housing provident 
funds to pay rent and subsidy for rental housing. According to rental price data of February 2018 released by Guangzhou rental agencies Association, average rental price in central area of Guangzhou is 54.97 yuan $/ \mathrm{m}^{2}$ each month, while average rental price in peripheral area is $33.47 \mathrm{yuan} / \mathrm{m}^{2}$ each month. Widening monthly rent and payments scissors has created a great demand for renting houses in the suburbs far from the city center. As a rapid urban railway transit, the subway connects the downtown area and the suburban, and reduces the commuting time of spatial mismatch of job-housing population. What impact will the subway have on the rental price of the surrounding residential housing? By constructing a hedonic price model, this paper selects Guangzhou Metro Line 2 as an example to research the impact of urban rail system on realty rental prices.

Existing research investigating the effects of subway on the price of the surrounding residential houses has focused on the residential price and rental price (Benjamin \& Sirmans, 1996), while rarely centered on rental price separately. When it comes to China, rent of house along the subway increases as the distance between the house and the nearest subway station to it decreases (Xiang, 2018). Furthermore, the average rent is the highest within 500 meters around the subway station (Bajic, 1983).

Although there are little papers about effect of urban railway system on the rents of surrounding residential houses, many researchers have investigated relationship between urban railway system and residential price. Most of them use metro to stand for urban railway system. According to the literature railway, system has both positive and negative influences on price of nearby residential. On one hand, the construction of rail transit will lead to an increase in housing price along the railway because of more convenient transportation. On the other hand, if the house is too near to railway or station, its price may be influenced negatively due to large passenger flow, security, noise, environmental pollution and other problems. In addition, the impact of urban railway system on residential buildings along the line is limited. In terms of the influential radius, foreign scholars believe that the average influential radius is between $0.5 \mathrm{~km}$ and $0.8 \mathrm{~km}$. Chinese scholars have not reached a consensus conclusion based on different urban subway line stations and calculation methods. Some results are shown in Table 1. Also, some researchers pointed out that spatial heterogeneity is an essential factor on this issue. Previous studies discussed the submarket effect of rail transit on surrounding property value increment quantitatively.

In general, there are few researches about nexus between subway and rental price of houses along the line. Therefore our results add new empirical evidence on this field. At the same time, under the background of China government developing residential leasing market, our study gives special attention to the law of rents around the subway. For real estate investors, they can know which distance the house from subway can gain the largest rental income. Renting out idle 
Table 1. Influencing range of metro line on residential price.

\begin{tabular}{ccc}
\hline Author & Research object & Influence radius \\
\hline (He \& Zheng, 2004) & Beijing Metro Line 13 & within $500 \mathrm{~m}$ \\
(Zheng \& Liu, 2005) & Shenzhen Metro & $400 \mathrm{~m}-600 \mathrm{~m}$ \\
$($ Wang, 2009) & Shanghai Metro Line 8 & $1 \mathrm{~km}-1.5 \mathrm{~km}$ \\
$($ Liu \& Hu, 2007) & Chongqing Metro Line 2 & $0.21 \mathrm{~km}-2.98 \mathrm{~km}$ \\
$($ Mei, Xu, Ouyang, \& Liu, 2011) & Guangzhou Metro Line 3 & $0.52 \mathrm{~km}-6.68 \mathrm{~km}$ \\
\hline
\end{tabular}

houses is conducive to decrease vacancy rate (availability rate). For tenant, they are able to know what factors will affect the rent. Our results will give some advices to tenants.

The remainder of the paper is organized as follows. In Section 2, we provide details on the Guangzhou Metro Line 2. Moreover, we describe the characteristic variables and the econometric approach used in this paper. In Section 3, we show some summary statistics based on data to describe current residential leasing market in contemporary Guangzhou. Then, the econometric evidence on the effects of subway on the rents of surrounding residential houses will be discussed. Section 4 we draw some conclusions with policy implications.

\section{Data and Approach}

\subsection{Data}

\subsubsection{Introduction of Guangzhou Metro Line 2}

Guangzhou Metro Line 2 is operated on 29th December 2002. There are 24 stations across Guangzhou Metro Line 2, 7of which are transfer stations. It is 31.8 kilometers long and spans four districts including Baiyun District, Yuexiu District, Haizhu District and Panyu District from north to south. The line connects suburban (Baiyun District and Panyu District) and central areas (Yuexiu District and Haizhu District). The Beijing Road and Jiangnan Xi two traditional business districts are located along the line. In addition, the line shortens the distance between Guangzhou Railway Station and Guangzhou South Railway Station, two important transportation hubs.

\subsubsection{Datasource}

This paper used data that were collected from the real estate rental service platform-Anjuke website (https://guangzhou.anjuke.com/). The website publishes information on dwellings to be rented. In fact, some houses to be rented are posted advertisements offline. Therefore, these types of samples cannot be collected. In order to collect data as comprehensive as possible, this paper chose the largest real estate rental service platform as data source. The principle of choosing survey samples is to select houses in different communities as much as possible, and collect only two houses in the same community. At the beginning, we are going to collect ten houses for rent around each station. However few housing information are advertised around some stations. We collect housing 
information about 215 houses for rent along the line 2 at the end. The real estate agency website advertises various information about houses, such as monthly rent, property of the houses (location, floor space, floor, amounts of rooms and halls etc.), neighborhood environment (distance from hospitals, parks, subway stations, etc.). Distance from the sample to Beijing Road and Jiangnan Xi business district can be obtained by the marking and ranging functions of Baidu map. Price of the land that the house located on is collected from the official website of Guangzhou Land Resources and Planning Commission. This website also established the level of residential land in four districts mentioned above. All geographic locations of subway station as well as houses are caught from Google Earth and Anjuke website electronic map.

\subsection{Approach}

\subsubsection{Hedonic Model}

In 1939, foreign scholar Court first proposed the hedonic price method and applied this method to establish the automobile price index. In the 1960s, the hedonic price method was applied to analyze residential market. Since then, the model has been widely used in real estate evaluation, compiling real estate price indices, and studying the impact of transportation routes on residential values. The Hedonic model considers that a commodity has many different characteristics, so a certain commodity can be described as a certain combination of the quantity and feature of the commodity. Various combinations of features will bring difference in commodity prices. Then, driven by the consumer's pursuit of maximizing the utility of the purchase, the highest cost that is willing to pay for each new feature is the implied price of the feature, that is, the quantification of the feature price. The construction of the feature price model includes the selection of function forms and feature variables. There are three commonly used functional forms: 1) linear model; 2) semi-logarithmic model; 3) log-linear model.

linear model: $\quad P_{i}=\alpha_{o}+\sum_{k=1}^{n} \alpha_{k} x_{k i}+\beta d_{i}+\varepsilon_{i}$

In the Equation (1), $P_{i}$ is the monthly rent of the ith house. $x_{k i}$ is the property of the ith house. $d_{i}$ is the distance between the house and the nearest subway station. $\alpha_{o}, \alpha_{k}, \beta$ are estimated parameters. With distance changes by one unit, the monthly rent change by $\beta$ unit.

semi-logarithmic mode: $\quad \ln P_{i}=\alpha_{o}+\sum_{k=1}^{n} \alpha_{k} x_{k i}+\beta d_{i}+\varepsilon$

In the Equation (2), the explained variable $\ln P_{i}$ is monthly rent of the ith house (in logs). Other variables are as same as those in Equation (1). With distance changes by one unit, the monthly rent change by $\beta \%$.

$$
\text { log-linear model: } \quad \ln P_{i}=\alpha_{o}+\sum_{k=1}^{n} \alpha_{k} \ln x_{k i}+\beta \ln d_{i}+\varepsilon_{\mathrm{i}}
$$

In the Equation (3), we take log of the explained variable and explaining variables. With distance changes by one percent, the monthly rent change by $\beta \%$. 


\subsubsection{Selection of Feature Variables}

Influence of subway on rent can't just base on the change in the distance between the rent and the subway station, because rent level is affected by various factors. Therefore, it is necessary to introduce the Hedonic model. Considering availability of data, this paper sets the characteristic variables from three aspects: architectural features, neighborhood environment and location features. According to the report of 2017 China residential leasing market published by Lianjia Institute, $70 \%$ of the tenants in major cities are young people of $20-30$ years old. So we take consumer preference of young people into account. Location features are evaluated by distance from the house to Beijing Road Trading Area, Jiangnan Xi Trading Area and Baiyun New Town Trading Area. What's more, house is unmovable and location conditions are the key factors affecting its price. If the house is located in the central city, according to the theory of land rent, the land price of the lot is high, then the high land cost will be transferred to the rent through the house price, so the land price is also an important factor affecting the rent. The characteristic variable system is shown in Table 2.

\subsubsection{Selection of the Model}

It was found that the semi-logarithmic model was better in terms of parameter estimation and goodness of fit. Finally, the semi-logarithmic model was chosen for research. The regression coefficient $\beta$ indicates distance changes by one unit, the monthly rent change by $\beta \%$.

\section{Evidence}

This paper uses Stata software to analysis. Guangzhou Metro Line 2 runs across the Baiyun District, Yuexiu District, Haizhu District and Panyu District. Considering environment and socio-economic conditions of these four regions are different, it is necessary to group 215 houses into three groups in order to discuss the impact of residential rent along the line separately. As a result, the samples were divided into three groups: the first group (G1) of houses from Jiahe Wanggang Station to the Feixiang Park Station in the Baiyun District, and the second group (G2) in the Sanyuanli-Haizhu Square zone of the Yuexiu District. The remaining samples around the subway station in Haizhu District and Panyu District are included in the third group (G3).

The three sets of samples were analyzed using a semi-logarithmic model. Since the Anjuke website only provides the real estate rent for the last 6 months to 3 years, it is impossible to compare the rent time series before and after the subway operation. All the data are cross-sectional data. There is no sequence correlation in the cross-section data. Furthermore, for the linear regression model, even if the disturbance term does not obey the normal distribution, the OLS is consistent and obeys the asymptotic normal distribution. Therefore, it is not necessary to test whether the disturbance term obeys the normal distribution, but needs to perform multicollinearity test and heteroscedasticity test before the regression. 
Table 2. Variables of the model.

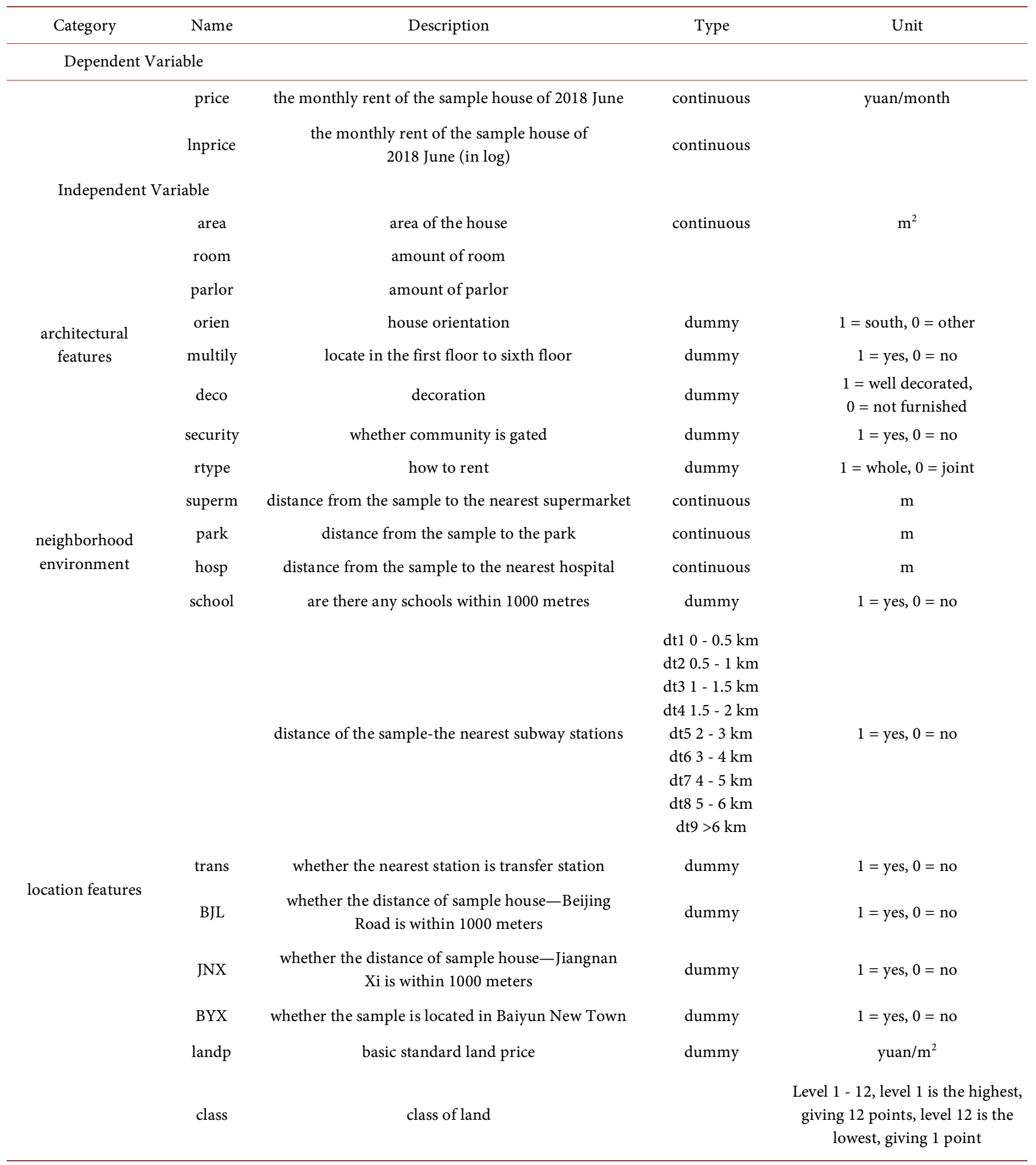

\subsection{Descriptive Statistical Analysis}

Table 3 displaces some descriptive statistics of three groups. The samples have different attributes in different subway sections and administrative districts.

1) The price of rent: the average rent of houses located in G2 is the highest, while it is the lowest in G1. When correlating group to administrative district, 
Table 3. Influencing range of metro line on residential price.

\begin{tabular}{|c|c|c|c|c|c|c|}
\hline Variable & Group & Max & Min & Average & Std. Dev & Amount \\
\hline \multirow{3}{*}{$\begin{array}{l}\text { monthly rent } \\
\text { (yuan) }\end{array}$} & G1 & $18,000.00$ & 700.00 & 3929.03 & 2871.93 & 62 \\
\hline & G2 & $12,000.00$ & 1600.00 & 4265.42 & 1868.88 & 67 \\
\hline & G3 & $13,000.00$ & 1300.00 & 3982.86 & 1898.44 & 86 \\
\hline \multirow{3}{*}{$\begin{array}{c}\text { rent } \\
\left.\text { (yuan } / \mathrm{m}^{2} / \mathrm{month}\right)\end{array}$} & G1 & 114.29 & 16.33 & 48.30 & 17.56 & 62 \\
\hline & G2 & 158.14 & 34.72 & 65.65 & 21.11 & 67 \\
\hline & G3 & 93.75 & 28.89 & 51.20 & 13.59 & 86 \\
\hline \multirow{3}{*}{$\begin{array}{l}\text { area } \\
\left(\mathrm{m}^{2}\right)\end{array}$} & G1 & 180.00 & 17.00 & 79.84 & 30.90 & 62 \\
\hline & G2 & 124.00 & 18.00 & 67.40 & 24.71 & 67 \\
\hline & G3 & 450.00 & 23.00 & 83.37 & 52.40 & 86 \\
\hline \multirow{3}{*}{ room } & G1 & 4.00 & 1.00 & 2.13 & 0.74 & 62 \\
\hline & G2 & 3.00 & 1.00 & 2.00 & 0.65 & 67 \\
\hline & G3 & 5.00 & 1.00 & 2.14 & 0.81 & 86 \\
\hline \multirow{3}{*}{ parlor } & G1 & 2.00 & 0.00 & 1.52 & 0.54 & 62 \\
\hline & G2 & 2.00 & 0.00 & 1.19 & 0.44 & 67 \\
\hline & G3 & 3.00 & 0.00 & 1.40 & 0.54 & 86 \\
\hline \multirow{3}{*}{$\begin{array}{c}\text { basic standard land } \\
\text { price } \\
\left(\text { yuan } / \mathrm{m}^{2}\right)\end{array}$} & G1 & $21,343.00$ & 8575.00 & $15,489.52$ & 3595.48 & 62 \\
\hline & G2 & $26,835.00$ & $14,842.00$ & $22,574.64$ & 4036.44 & 67 \\
\hline & G3 & $25,599.00$ & 9102.00 & $15,007.33$ & 3551.97 & 86 \\
\hline
\end{tabular}

the rent level of Yuexiu District is 65.650 yuan $/ \mathrm{m}^{2}$ per month, Baiyun District is 48.296, Haizhu and Panyu District is 51.200.

2) Rental area: The minimum rental area of each group is less than $25 \mathrm{~m}^{2}$, which is a joint rent. The largest area is a villa in Panyu District with a rental area of $450 \mathrm{~m}^{2}$. The average rental area of houses in Haizhu and Panyu District (G3) is the largest, while the average area of samples of Yuexiu District (G2) is the smallest. With development of the southern part of Guangzhou, there are more and more new residential areas in Panyu District with the purpose of lessening population stress of the central zone. On one hand, due to low land prices, real estate developers design community of low density and low volume ratio. The size of the apartment is mostly 3 rooms and 2 halls. The building area of house is generally over $100 \mathrm{~m}^{2}$, so the area of the renting unit is large. On the other hand, the Yuexiu District and Haizhu District are traditional zones in Guangzhou. Urban lands are intensively used in these two districts. There is no doubt that average areas of houses are small.

3) Basic standard land price: According to the 2017 residential land level map of Guangzhou, basic land price of Yuexiu District was the highest, with a mean value of 22,574.640 yuan, and the lowest was Haizhu District and Panyu District $(15,007.330$ yuan). This is also in line with the current level of social and economic development in these four districts. 


\subsection{The effect of Guangzhou Metro Line 2 on Residential Rent of Houses}

\subsubsection{Jiahe Wanggang Station-Feixiang Park Station Zone of Baiyun District}

Firstly, both heteroscedasticity test and multicollinearity test should be operated. It is found that Prob $>$ chi $2=0.9528$, so the assumption of the same variance can't be rejected (shown in Table 4). However, there is multicollinearity and we regress by stepwise in order to deal with multicollinearity.

Table 5 shows the results for the regression. As can be seen, the parameters of these five variables are highly significant. However, eight dummy variables $\mathrm{dt1}$-dt9 that stand for distance between houses and subway station are nonsignificant at $5 \%$ significance level. Some variables such as area of houses, amount of rooms, rental method and distance from the sample to the nearest hospital and supermarket have influence on the rent. As shown in Table 5, "area" variable is significant at $5 \%$ significance level. In details, for $1 \mathrm{~m}^{2}$ increase in rental area, the monthly rent increases by an average of $0.91 \%$. For each additional room, the monthly rent increased by an average of $18.78 \%$. When the value of the rental method is changed from 0 to 1 , that is, the house is overall rented, and the average rent increases by $44.59 \%$. When it comes to the neighborhood environment, distance from the house to the nearest supermarket has positive influence on the rent, while distance from the same house to hospital will bring negative influence on the rent.

Most of domestic researches have proved that the subway leads to rise of housing prices along the line. We predict that residential prices are the capitalization of rents and the sum of the present value of future rental income, so rents should also show the same pattern. However, the regression results show that the Jiahe Wanggang Station-Feixiang Park section has no significant impact on the rent of the houses along the line, which is inconsistent with the expected positive effect. Jiahe Wanggang Station-Feixiang Park section locates in the area of Baiyun New town. The Baiyun New town is positioned as the headquarters economic cluster. A number of important industrial projects are under construction. There are more than 1400 bus lines in Baiyun District. Therefore, superior location conditions and a variety of transportation options will attenuate the subway effect. In addition, the weight of subway is relatively low for the reason that there are many factors will affect the rent.

Chinese Scholar (Xie, 2004) explored the reasonable range of house price-rent ratio from the potential investment of purchase behavior, and studied the house price-rent ratio of cities such as Beijing and Shanghai. He drew a conclusion that

Table 4. The heteroscedasticity test of Jiahe Wanggang-Feixiang Park zone.

\begin{tabular}{cc}
\hline Breusch-Pagan/Cook-Weisberg test for heteroskedasticity \\
Ho: Constant variance; Variables: fitted values of lnprice
\end{tabular}


Table 5. The estimation results of Jiahe Wanggang-Feixiang Park zone.

\begin{tabular}{cccccc}
\hline Group & Variable & Coef. & Std. Dev & $\mathrm{t}$ & $P>|\mathrm{t}|$ \\
\hline \multirow{6}{*}{ G1 } & area $^{* * *}$ & 0.009 & 0.002 & 4.940 & 0.000 \\
& room $^{* * *}$ & 0.188 & 0.077 & 2.440 & 0.018 \\
& hosp $^{* * *}$ & 0.000 & 0.000 & 4.330 & 0.000 \\
& rtype $^{* * *}$ & 0.446 & 0.111 & 4.020 & 0.000 \\
& superm & & & \\
& & -0.000 & 0.000 & -2.270 & 0.027 \\
& _cons & & & \\
& 6.430 & 0.151 & 42.540 & 0.000 \\
\hline
\end{tabular}

Notes: ${ }^{\star *}$ denote statistical significance at the $5 \%$ level.

rent is related to house price. Another scholar used the price data and rent data from 1998 to 2004 in Shanghai to conduct a Granger causality test and found that Shanghai's housing prices and rents were basically independent (Cui, 2006). In summary, the current domestic view mainly believes that house prices are not related to rents. Therefore, subway can affect the residential price of houses along the line positively but it may have no effect on the rent.

The conclusion that Jiahe Wanggang Station-Feixiang Park section of Metro Line 2 has no significant impact on the rent of residential houses along the line remains to be verified.

\subsubsection{Sanyuanli-Haizhu Square Station Zone of Yuexiu District}

Firstly, both heteroscedasticity test and multicollinearity test should be operated. It is found that Prob $>$ chi $2=0.5445$, so the assumption of the same variance can't be rejected (shown in Table 6).

Table 7 shows the results for the regression. Similar with the result of Table 5, eight dummy variables dt 1 - dt9 that stand for distance between houses and subway station are nonsignificant at $5 \%$ significance level too. Some variables such as area of houses, amount of rooms and parlors, distance from the sample to the nearest supermarket, basic land price and rental method have influence on the rent. Whether the sample house locates on the lower floor also influence the rent. However, except for the large regression coefficient of the rent type and area variable, the regression coefficients of the remaining variables are extremely small. Result shows that the 67 houses for rent in Yuexiu District have quite similar living conditions, such as supermarkets, schools, hospitals, etc. All samples located in the zone have high basic land price. Internal factors including rent type as well as areas made great contribution to rent.

Why the subway has no significant impact on the rent in the zone? Firstly, there are amount of great education resources in Sanyuanli-Haizhu Square zone. The rental advertisements on Anjuke website also emphasize the level and number of schools around the section, reflecting the needs and preferences of the tenants in the section. The tenants take educational resources in the first place. Except for education resource, tenants emphasize on the quality of the house itself and the nearby living facilities rather than the distance from the 
Table 6. The heteroscedasticity test of Jiahe Sanyuanli-Haizhu Square zone.

\begin{tabular}{cc}
\hline Breusch-Pagan/Cook-Weisberg test for heteroskedasticity \\
Ho: Constant variance; Variables: fitted values of lnp \\
\hline chi2 (1) \\
Prob $>$ chi2 & 0.37 \\
\hline
\end{tabular}

Table 7. The estimation results of Sanyuanli-Haizhu Square zone.

\begin{tabular}{|c|c|c|c|c|c|}
\hline Group & Variable & Coef. & Std. Dev & $\mathrm{t}$ & $P>|\mathrm{t}|$ \\
\hline \multirow{9}{*}{ G2 } & $\operatorname{area}^{* * *}$ & 0.007 & 0.002 & 4.490 & 0.000 \\
\hline & $\operatorname{room}^{* * *}$ & 0.109 & 0.053 & 2.070 & 0.043 \\
\hline & parlor $* * *$ & 0.152 & 0.071 & 2.130 & 0.037 \\
\hline & hosp $p^{* * *}$ & 0.000 & 0.000 & 2.560 & 0.013 \\
\hline & multily & -0.185 & 0.0579 & -3.210 & 0.002 \\
\hline & landp $p^{* * *}$ & 0.000 & 0.000 & 3.350 & 0.001 \\
\hline & superm $^{\star * *}$ & 0.000 & 0.000 & 2.590 & 0.012 \\
\hline & rtype $^{* * *}$ & 0.4223 & 0.151 & 2.800 & 0.007 \\
\hline & _cons ${ }^{\star * *}$ & 6.179 & 0.240 & 25.720 & 0.000 \\
\hline
\end{tabular}

Notes: ${ }^{* *}$ denote statistical significance at the $5 \%$ level.

subway. Moreover, there is high density distribution of subway stations in this section. Traditional business districts such as Beijing Road, Haizhu Square and Guangzhou Railway Station all located in this zone. Therefore, there are few differences between samples due to convenient transportation and living facilities. The level of rent depends on the quality of the house. Yuexiu District is the traditional central area of Guangzhou. Convenient and various transportation modes reduce some of the "Metro effect". At the same time, there are many factors will influence the rent, and the influence of rail transit is limited (Hou \& Yan, 2006).

\subsubsection{Workers' Cultural Palace-Guangzhou South Railway Station Zone of Haizhu and Panyu District}

Both heteroscedasticity test and multicollinearity test should be operated. It is found that Prob $>$ chi $2=0.1340$, so the assumption of the same variance can't be rejected (shown in Table 8). However, there is multicollinearity and we regress by stepwise in order to deal with multicollinearity.

Showing in Table 9, the Variables of neighborhood environment level are insignificant; on the contrary, other variables can affect the dependent variable.

First of all, variables from the level of building features will be discussed. As shown in Table 9, "area" variable is significant at $5 \%$ significance level. If the area of the house increases by $1 \mathrm{~m}^{2}$, the monthly rent will increase by $0.3 \%$ on average. The rent will increase by $17.097 \%$ with each additional room. Similarly, the rent will increase by $9.835 \%$ if the house has one more parlor. The monthly rent of the house on lower floors is $8.90 \%$ lower than the monthly rent on the middle and high floors due to bad daylighting and ventilation. And the rent of 
Table 8. The heteroscedasticity test of 2nd Workers' Cultural Palace-Guangzhou South Railway Station zone.

\begin{tabular}{cc}
\hline \multicolumn{2}{l}{$\begin{array}{l}\text { Breusch-Pagan/Cook-Weisberg test for heteroskedasticity } \\
\text { Ho: Constant variance; Variables: fitted values of lnprice }\end{array}$} \\
\hline chi2 (1) & 2.25 \\
Prob $>$ chi2 & 0.1340 \\
\hline
\end{tabular}

Table 9. The estimation results of the 2nd Workers' Cultural Palace-Guangzhou South Railway Station zone.

\begin{tabular}{|c|c|c|c|c|c|}
\hline Group & Variable & Coef. & Std. Dev & $\mathrm{t}$ & $P>|\mathrm{t}|$ \\
\hline \multirow{11}{*}{ G3 } & $\operatorname{area}^{* * *}$ & 0.003 & 0.001 & 4.830 & 0.000 \\
\hline & $\operatorname{room}^{* * *}$ & 0.171 & 0.045 & 3.790 & 0.000 \\
\hline & parlor ${ }^{* * *}$ & 0.098 & 0.045 & 2.160 & 0.034 \\
\hline & $\mathrm{dt} 4^{* * *}$ & 0.298 & 0.133 & 2.230 & 0.028 \\
\hline & multily & -0.089 & 0.040 & -2.240 & 0.028 \\
\hline & $\mathrm{dt} 3^{* * *}$ & 0.412 & 0.115 & 3.560 & 0.001 \\
\hline & security ${ }^{* * *}$ & 0.173 & 0.055 & 3.150 & 0.002 \\
\hline & $\mathrm{dt}^{* * *}$ & 0.450 & 0.112 & 4.010 & 0.000 \\
\hline & $\mathrm{dt} 2^{* * *}$ & 0.400 & 0.108 & 3.690 & 0.000 \\
\hline & landp $p^{* \star *}$ & 0.000 & 0.000 & 2.750 & 0.007 \\
\hline & _cons ${ }^{* * *}$ & 6.690 & 0.147 & 45.440 & 0.000 \\
\hline
\end{tabular}

Notes: ${ }^{* *}$ denote statistical significance at the $5 \%$ level.

the house without elevator is lower than that with elevator. Finally, the rent of closed management of the community is $17.25958 \%$ more than the rent of the non-closed management, which also reflects the increasing emphasis on housing security and privacy.

At $5 \%$ significance level, dt1, dt2, dt3, dt4, and basic standard land price have significant effects on rent. Under the premise that the other variables in the regression model remain unchanged, compared with the sample located out of 0.5 $\mathrm{km}$ from the nearest subway station, the rent of residential sample within 0 - 0.5 $\mathrm{km}$ from the station is higher. The rent of latter one is $45.02589 \%$ higher than the former one. When the distance increases to $(0.5,1 \mathrm{~km})$, the rent of sample within $0.5-1 \mathrm{~km}$ from the station is $39.984 \%$ higher than that outside the distance interval. At the distance interval of $(1,1.5 \mathrm{~km})$, the monthly rent increased by an average of $41.1569 \%$ compared with the rent of house not in the section. In addition, at the distance interval $(1.5,2 \mathrm{~km})$, the average monthly rent will only increase by $29.825 \%$. The regression coefficient of the basic land price is extremely small that indicates it has few significance on rent.

According to the results of OLS estimates, within radius of $0-2000 \mathrm{~m}$, the ratio of rent (in $\log$ form) is $\ln \mathrm{P}_{1}: \ln \mathrm{P}_{2}: \ln \mathrm{P}_{3}: \ln \mathrm{P}_{4}=$ 0.4502589:0.3998473:0.4115694:0.2982519. Through antilogarithm calculation, 
the ratios of the monthly rent at different distance section is $\mathrm{P}_{1}: \mathrm{P}_{2}: \mathrm{P}_{3}: \mathrm{P}_{4}=$ $\mathrm{e}^{0.4502589}: \mathrm{e}^{0.3998473}: \mathrm{e}^{0.4115694}: \mathrm{e}^{0.2982519}=1.569: 1.492: 1.510: 1$. In detail, the average increase in monthly rent of houses in Workers' Cultural Palace-Guangzhou South Railway Station zone is $52.37 \%$. The closer the house is to the subway station, the higher are the monthly rents. The rents of residential within $0.5 \mathrm{~km}, 0.5$ $\mathrm{km}$ to $1 \mathrm{~km}$, and $1 \mathrm{~km}$ to $1.5 \mathrm{~km}$ from the subway station are $56.9 \%, 49.2 \%$ and $51 \%$ higher than the monthly rents of houses in the range of $1.5 \mathrm{~km}$ to $2 \mathrm{~km}$ separately. So the result indicated that the section of Guangzhou Metro Line 2 is able to affect the rent of houses positively within $1.5 \mathrm{~km}$. Furtherly, the effect is the strongest within $500 \mathrm{~m}$, while the monthly rental gap between the two ranges of $0.5 \mathrm{~km}$ to $1 \mathrm{~km}$ and $1 \mathrm{~km}$ to $1.5 \mathrm{~km}$ is shrinking.

Why just only Workers' Cultural Palace-Guangzhou South Railway Station section has a significant impact on the monthly rent of residential houses along the line? The main reason is that the impact of the subway on rent of houses located in suburban is more significant than the impact in the central urban area. The section connects the Panyu District and the Haizhu District. Panyu District is far from the downtown, and the transportation infrastructure is relatively backward. The alternative effect of other modes of transportation on the subway is not so strong to reduce the influence from subway. The construction of the subway will include Panyu District into the "half-hour life circle", which will reduce the travel time and economic cost of surrounding residents. It is good for the transportation improvement. Potential tenant will tend to choose a house near the subway to save travel costs in Panyu District. When it comes to the Workers' Cultural Palace-Chexiaonan part, even although it locates in Haizhu District, the subway extends south to Panyu District, and there is still a certain distance from the Tianhe CBD. Therefore, potential tenant in this section will also consider travel cost, and will also prefer houses near the subway.

\section{Conclusion}

Empirically, a contribution of this study is research the impact of urban rail system on realty rental prices, which is few scholars focus on. Moreover monthly rents of houses within different distances have different effect on monthly rent. This widened the scope of the study to include parametric analyses of impact of urban rail system on realty rental prices. This paper established a Hedonic model to study the impact of the subway on monthly rent of residential along the Guangzhou Metro Line 2 by collecting 225 houses to be rented as samples. The results show how the distance between houses and subway station can has positive influence on monthly rent of houses. The closer the house is to the subway station, the higher are the monthly rents. This paper used the distance between houses and subway station to stand for urban railway system. Results are as follow.

1) There is difference in the influence of urban rail transit on the central and peripheral areas of the city. In a word, subway can bring more positive effect on 
suburban than the central area of city. Impact of urban rail transit on residential rent in central zone is limited due to great location conditions and various supporting facilities. Another reason is the negative impact of noise caused by urban rail transit and large passenger traffic. Therefore, the impact on the residential rent price in the central urban area is not significant.

2) The radius of influence of subway on house is $1.5 \mathrm{~km}$. The closer the house is to the subway station, the higher are the monthly rents. Guangzhou Metro Line 2 is able to affect the rent of houses positively within $1.5 \mathrm{~km}$. Further, the effect is the strongest within $500 \mathrm{~m}$, while the monthly rental gap between the two ranges of $0.5 \mathrm{~km}$ to $1 \mathrm{~km}$ and $1 \mathrm{~km}$ to $1.5 \mathrm{~km}$ is shrinking.

3) The empirical results show that the monthly rents of houses within $0.5 \mathrm{~km}$, $0.5 \mathrm{~km}-1 \mathrm{~km}$, and $1 \mathrm{~km}-1.5 \mathrm{~km}$ from the subway station are $56.9 \%, 49.2 \%$ and $51 \%$ higher than the monthly rents of houses outside the affected area, respectively. That is to say, the monthly rent for houses within $500 \mathrm{~m}$ from the subway station is the highest. For investors, if the surrounding living environment and facilities are similar, they can buy houses for rent within $1.5 \mathrm{~km}$ from the subway station, which will benefit them a lot. For one thing, investors can get considerable award. For another thing, it can increase the occupancy rate of vacant homes.

4) For potential tenants, they can consider renting a house in the suburbs or near suburb. The better distance is within a radius of $0.5 \mathrm{~km}$ to $1 \mathrm{~km}$ from the subway station according to their financial affordability. The distance is moderate, as the monthly rent of the house within $500 \mathrm{~m}$ from the subway station is the highest, and the house outside $1 \mathrm{~km}$ is a little far from the subway station.

This paper still has some limitations. Firstly, some landlords only post advertisements offline or rent to their acquaintances. This kind of sample is difficult to collect comprehensively. Further work could take them into account. We can also use Python to collect data from more real estate rental service platform websites. Secondly, as the results shown, impact of urban rail transit on residential rent in central zone is nonsignificant. Great location conditions and various supporting facilities affect the residential rent more rather than urban railway. Further empirical work could improve the variable system and measure effect of urban railway on realty rental prices as accurately as possible.

\section{Conflicts of Interest}

The author declares no conflicts of interest regarding the publication of this paper.

\section{References}

Bajic, V. (1983). The Effects of a New Subway Line on Housing Prices in Metropolitan Toronto. Urban Studies, 20, 147-158. https://doi.org/10.1080/00420988320080291

Benjamin, J. D., \& Sirmans, G. S. (1996). Mass Transportation, Apartment Rent and Property Values. Real Estate Research, 12, 1-8.

https://doi.org/10.1007/978-94-009-1802-3_1 
Cui, G. C. (2006). Research on the Relationship between House Price, Land Price and Rent in Shanghai. Real Estate Market, 4, 4-6.

He, J. H., \& Zheng, S. Q. (2004). Can New Subways Increase Residential Prices?-Taking Beijing Metro Line 13 as an Example. Urban Development, 11, 36-38.

Hou, A. M., \& Yan, Q. (2006). Overview of the Impact of Rail Transit on Urban Housing Development. Urban Problems, 6, 32-38.

Liu, G. W., \& Hu, G. Q. (2007). Scope and Time Study of the Impact of Rail Transit on Housing Price-An Empirical Analysis Based on Chongqing Rail Transit Line 2. Urban Development Research, 14, 83-87.

Mei, Z. X., Xu, W. J., Ouyang, J., \& Liu, J. (2011). Time and Space Effects of Guangzhou Metro Line 3 on Surrounding Residential Prices. Geography Science, 31, 836-842.

Wang, L. (2009). Research on the Impact of Urban Rail Transit on Housing Price-Quantitative Analysis Based on Characteristic Price Model. Regional Research and Development, 28, 57-61+70.

Xiang, W. (2018). The Influence of Subway Commuting Conditions and Site Distance on Rent Price-Taking Beijing Subway Line 5 as an Example. Journal of Jishou University (Natural Science Edition), 39, 93-96.

Xie, Y. L. (2004). Research on Beijing-Shanghai-Shenhang House Price Based on House Price Rent Ratio. Zhejiang Economy, 10, 25-28.

Zheng, J. F., \& Liu, H. Y. (2005). The Impact of Shenzhen Metro Construction on the Value of Residential Buildings around the Site. Journal of the China Railway Society, 27, 11-18. 